\title{
PsychMate: Providing psychology majors the tools to do real experiments and learn empirical methods
}

\author{
AMY ESCHMAN \\ Psychology Software Tools, Inc., Pittsburgh, Pennsylvania \\ JAMES ST. JAMES \\ Millikin University, Decatur, Illinois \\ WALTER SCHNEIDER \\ Psychology Software Tools, Inc., Pittsburgh, Pennsylvania \\ and University of Pittsburgh, Pittsburgh, Pennsylvania \\ and \\ ANTHONY ZUCCOLOTTO \\ Psychology Software Tools, Inc., Pittsburgh, Pennsylvania
}

\begin{abstract}
PsychMate is a set of software tools for undergraduate psychology students to run, develop, and analyze computerized experiments. It includes 30 psychological experiments in the areas of perception, cognition, social psychology, human factors, and cognitive neuroscience. Students run experiments themselves and see basic results immediately. The automatic spreadsheet analysis forms allow them to aggregate data and create analyses, presentations, and Web pages with a single click. Students can use the Psychology Experiment Authoring Kit experiment editor to create their own experiments in minutes and run experiments with other students using Web-based experiment-management tools. The BrainTutor and BrainViewer applications teach brain anatomy and permit students to analyze fMRI brain imaging data from subjects who have performed the same memory experiments in which they participated. PsychMate has been used in 83 classes in which 1,533 students submitted 5,464 completed experiments with few (less than 1\%) requests for help and a very positive rating of the research experience.
\end{abstract}

Most college psychology departments seek to provide their students with some laboratory experience and require them to take a research methods course (see Hornby \& Anderson, 1994; Williams, McGraw, \& Tew, 1999). Teaching these courses is challenging, given the limited budget, time, and resources available to psychology laboratory instruction. PsychMate addresses these challenges by providing a comprehensive set of tools to enable the psychology major to learn and use a variety of empirical research methods. Conceptually, PsychMate is targeted to meet a student's wide range of computing needs, including running experiments, analyzing results, creating computerized experiments, exploring brain anatomy,

This work was supported in part by NIH Grant 1R43MH072020-01: Managing Complexity in Psychology Experiment Generation. PEAK and PsychMate are products of Psychology Software Tools, Inc. (www.pstnet. com), 2050 Ardmore Boulevard, Suite 200, Pittsburgh, PA 15221. Correspondence should be addressed to W. Schneider, LRDC Building, 3939 O'Hara Street, University of Pittsburgh, Pittsburgh, PA 15260 (e-mail:wws@pitt.edu).

Editor's note: One or more of the authors has a direct financial interest in some of the software or hardware described in this article. viewing brain imaging data, developing questionnaires, and coding videos/events. The major goal of PsychMate is to provide psychology instructors and students with the tools to enhance the students' empirical training and experience in methods courses and throughout their undergraduate careers.

PsychMate provides an integrated collection of programs that run on computers using Microsoft Windows. As a comprehensive tool for undergraduate psychology instruction, PsychMate is designed to introduce students to classic and current experiments in psychology. PsychMate teaches students research methods by providing them with tools that allow them to create their own experiments in a single laboratory session. The act of creating an experiment allows contextualizing knowledge of experimental development, design, execution, analysis, and scientific communication. Running classic experiments provides a good understanding of the designs and results that have shaped experimental psychology.

PsychMate is a client-server application using the Internet for data submission and retrieval while using desktop experimental control to maintain timing precision. It includes: (1) a library of 30 robust paradigms in the areas 
of perception, cognition, cognitive neuroscience, social psychology, and human factors psychology; (2) automatic Web-based management of all individual, section, and class data; (3) automatic analysis and generation of graphs and spreadsheets, PowerPoint presentations, and HTML files for creating Web pages; (4) a Psychology Experiment Authoring Kit (PEAK; Schneider, Bolger, Eschman, Neff, \& Zuccolotto, 2005) that can be learned in $2 \mathrm{~h}$ and allows students to create novel computerized experiments in minutes; (5) Web-based experiment monitoring software to enable students to run class research projects with other students; (6) a BrainTutor to examine cortical areas; and (7) a BrainExaminer to examine data in functional imaging. These are all bundled in a common application launcher interface and provided at modest student pricing (less than most introductory textbooks), with no cost to the department.

PsychMate can operate on student or laboratory Microsoft Windows-based computers (access to the Internet is also required for product activation and submission of student data). The toolkit is designed to provide psychology majors with packages they can use in multiple courses and for completion of novel research projects. Extensive tools are provided to enable instructors with modest computer skills to develop and manage laboratories, requiring the instructors to spend less than an hour a week on preparation of materials.

Psychology views itself as primarily an empirical science (e.g., the vast majority of introductory textbooks in this field are devoted to empirical results). Yet the typical psychology major's undergraduate experience is of a discipline that often seems to be a taxonomy of past results. Psychology is a young science in which many questions are actively being explored and, in fact, students trained in research methods can discover new phenomena. However, the contrast between psychology and other empirical sciences is sharp. At the University of Pittsburgh, the psychology major spends about $13 \%$ of his or her class time in laboratory courses. In contrast, chemistry majors spend $58 \%$ of their class time in laboratories (based on required courses).

The learning experiences of psychology majors can be greatly aided by running experiments on themselves and then allowing them to analyze their own and group data. In addition, when students work on developing their own experiments they develop a much stronger foundation of basic research concepts such as control, independent and dependent variables, hypothesis testing, and statistical methods.

Nevertheless, the motivated instructor faces daunting challenges when teaching empirical computer-based methods courses, including: (1) limited, rudimentary computer skills of many students; (2) large class sizes; (3) limited laboratory space; (4) minimal budgets; (5) uncooperative network/computer support; (6) the need for a wide range of paradigms across disciplines; (7) the need for robust paradigms that have a high probability of showing the intended effect; (8) limited skills of teach- ing assistants; (9) limited laboratory time to teach the basics, execute sample experiments, and run and analyze individual projects; and (10) very limited instructor time to develop or enhance materials.

To address these challenges, PsychMate provides a set of tools with very comprehensive teaching materials. An instructor can, in $1 \mathrm{~h}$, select several experiments that can be utilized as the basis for the course. All student tracking is done automatically through Internet uploads to servers provided by the publisher (Psychology Software Tools, Inc.), and data files are downloaded to the instructors' computers upon request. The results from a class can be downloaded in a few minutes and analyzed automatically, generating Excel tables, PowerPoint slides, and Web pages. When the instructor has a question, there is one place to e-mail or telephone for support.

Many software packages provide students with experiment libraries (see http://psych.hanover.edu/Krantz/ software.html for 20). Psychology has a rich history of undergraduate computer tools for running experiments, including MacLaboratory (Chute, 1986), MEL LAB (St. James, Schneider, \& Rodgers, 1994), Projects (Sorkin, 1997), SuperLab LT (Chase \& Abboud, 1997), PsychExps (Williams et al., 1999), Laboratory in Cognition and Perception (Levy \& Ransdell, 2000), and CogLab (Francis, Neath, Mackewn, \& Goldthwaite, 2004). These efforts have mostly focused on providing packages for running experiments that will collect data using student subjects and providing between 20 and 30 experiments that students can run on themselves. Some of them allow looking only at individual data, and others merge across subjects. Most allow little, if any, modification of the experiments, and those that do may require getting into specialized scripting languages.

This project combines the work of previous efforts (Cohen, MacWhinney, Flatt, \& Provost, 1993; MacWhinney, St. James, Schunn, Li, \& Schneider, 2001; St. James, 1989; St. James \& Schneider, 1991; Schneider, 1988) in an integrated system with a wider range of paradigms and support tools than has ever before been provided. PsychMate offers 30 experiments and has larger goals of providing paradigms and additional tools that can help students to understand the methods and power of empirical science and develop skills that could be effectively employed in psychology research or applied domains (e.g., usability testing, learning, or product design). PsychMate provides more extensive processing data, greater flexibility for students to create their own experiments, and a wider range of tools than previous experiment libraries.

\section{PsychMate Experiment Library, Data and Application Management}

The PsychMate interface is a central base from which students can participate in experiments, manage data, or run special applications. Students use the PsychMate experiment library to participate in real experiments, not simple demonstrations or simulations. PsychMate enables them to take part in an expanding library of classic 
psychology experiments (currently 30) and see immediate plots and tables of their own real data. The experiments are selected and designed so that $90 \%$ of students are expected to replicate the main contrasts in their own data at the end of a run. The experiments are run with millisecond presentation accuracy and centisecond reporting of reaction times. The software includes an experiment launcher (see Figure 1) to allow students to quickly and easily complete the experiments. Data submission occurs automatically when students are connected to the Internet, or students may use the Student Organizer to run experiments offline and submit the results at a later time.

Students run the experiment either in demo or full mode. Figure 2 shows a sample screen from the rotation of mental images experiment. After running an experiment, students can examine, print, and copy (e.g., into a laboratory report) graphs and tables of their results. Figure 3 shows a sample graph available to the student after running the attentional interference and Stroop effect experiment.

The data path for the system is shown in Figure 4. The student can run the experiment on his or her own computer, or on a campus laboratory computer. ${ }^{1}$ If the machine is connected to the Internet, the data are automatically shipped to the publisher's secure Web server and then to a preexisting class that is set up by the instructor. If an Internet connection is not available, students may use a removable medium (e.g., floppy disk, memory stick) to save their data until they are able to connect. Once the data are submitted by the students, the instructor can download the individual data files and then merge them into a master file for group data analysis. The instructor is also provided with a summary of student participation. Instructors can also give students the option to download the group data. Note that the instructor does not need to worry about issues such as shared disk space, protections, data submission, or student tracking, since this is all monitored by PsychMate. The instructor must simply download the data to the local machine for analysis.

Considerable care is taken to provide student anonymity as to the specific data files. The instructor is provided with a summary of student participation in order to track which students have completed each of the experiments and to assign credit (see Figure 5). These data are provided after $20 \%$ of the class has submitted data. However, the instructor is not informed of each student's subject number. Only the student knows his or her own subject number and can therefore identify his or her own data within the group data (which helps students to become invested in the data set and to attend to contrasts between their data, the section data, and the class data).

The instructor can retrieve data files from the server with a single click to analyze single subject or group data files using the many prespecified data analyses (see Figure 6). This saves hours of preparation time. PsychMate can automatically analyze students' data and generate class materials for each lesson in Excel spreadsheets, PowerPoint, or HTML format. The students are encouraged to look at their personal data, the section data, and the full course data. Seeing how variability changes across levels of aggregation helps students to understand variability and statistical methods.

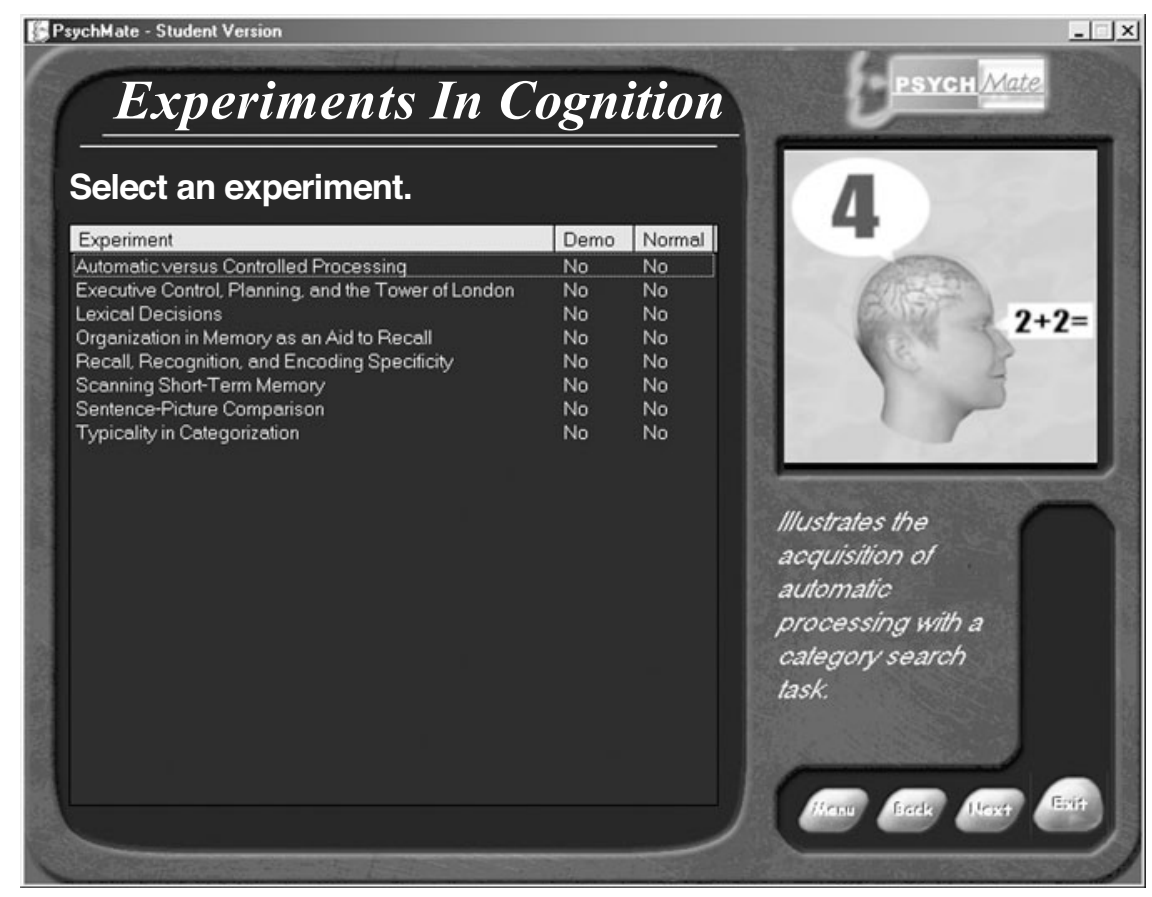

Figure 1. PsychMate cognition category experiment selection screen. 


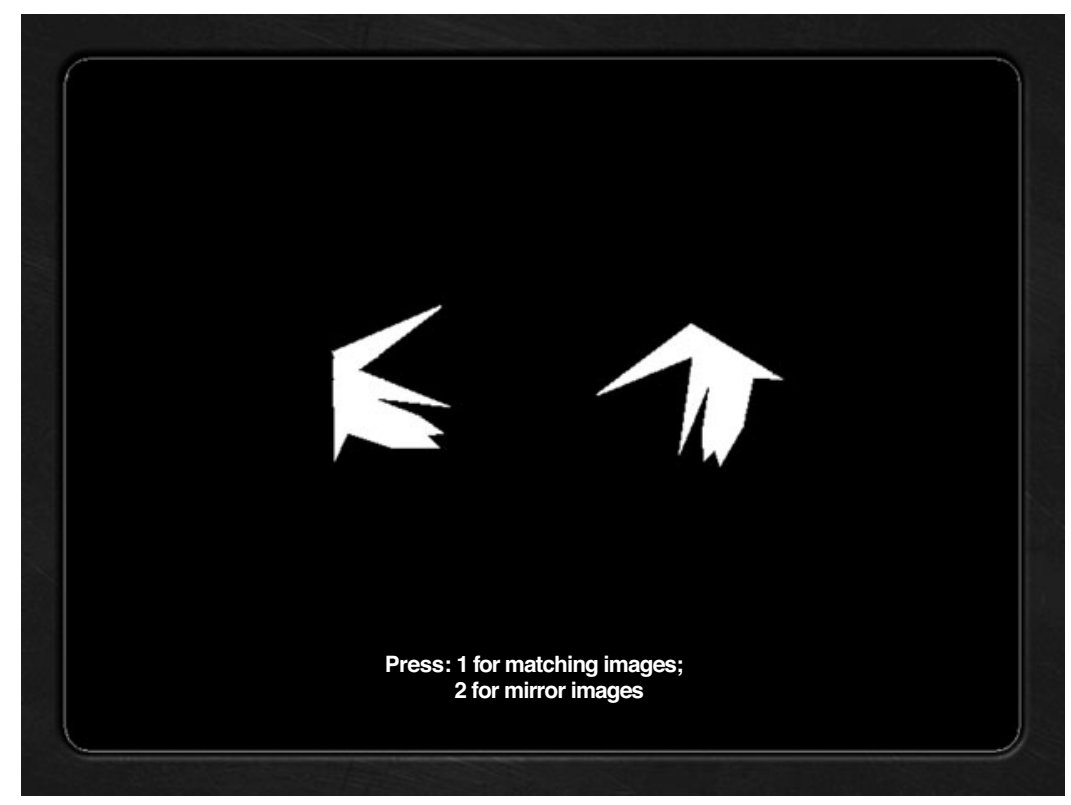

Figure 2. Sample screen from the mental rotation probe trial.

Data analysis. The analyses typically provided for each experiment include: (1) the basic analysis - mean reaction time or accuracy as a function of the principal independent variables; (2) a plot of each student's data on the same figure to illustrate intersubject variability; (3) a plot of accuracy for each student, to permit filtering of outliers; (4) a plot of the reaction time distribution; and (5) a trial-by-trial plot of reaction times, to illustrate variability at the trial level. These plots can be output as PowerPoint slides and rapidly converted into materials for a lecture. The data analysis is based on the beta program operation of PsychMate in 2004. The data were taken from 83 classes, 69 instructors, and 1,533 students, for a total 5,464 experimental sessions completed.

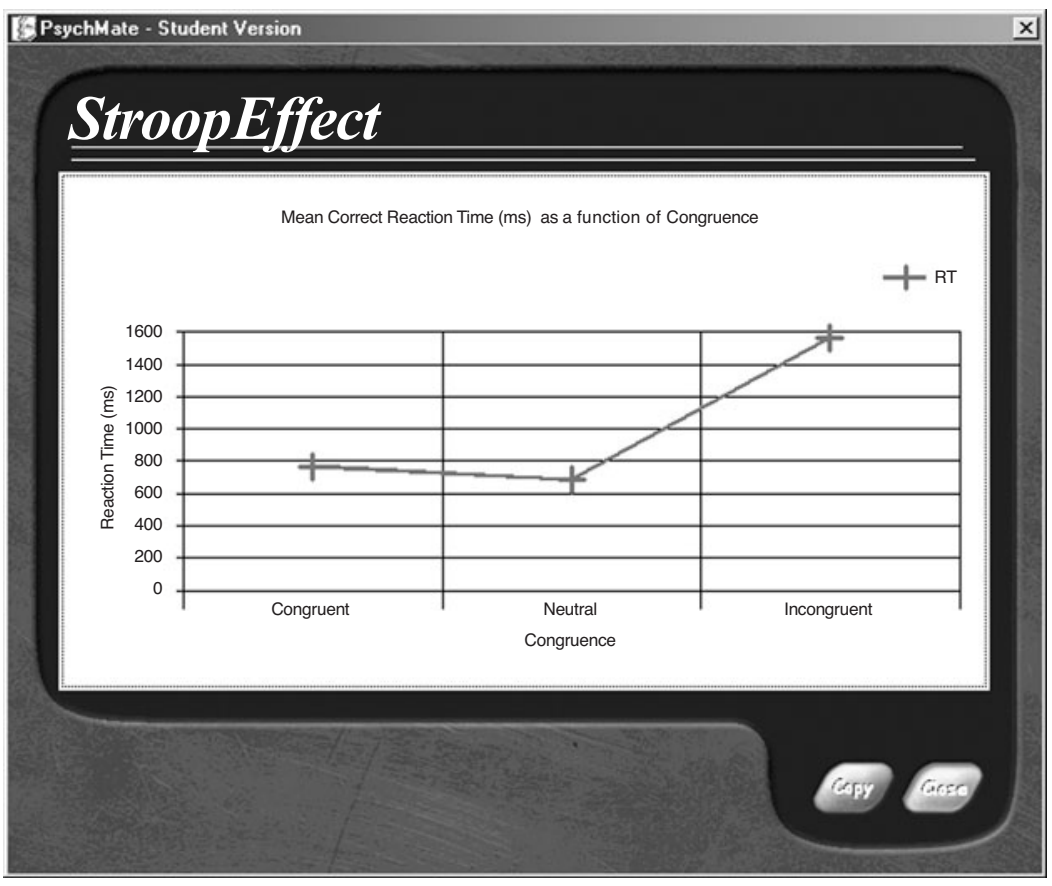

Figure 3. Sample single-subject reaction time plot. 


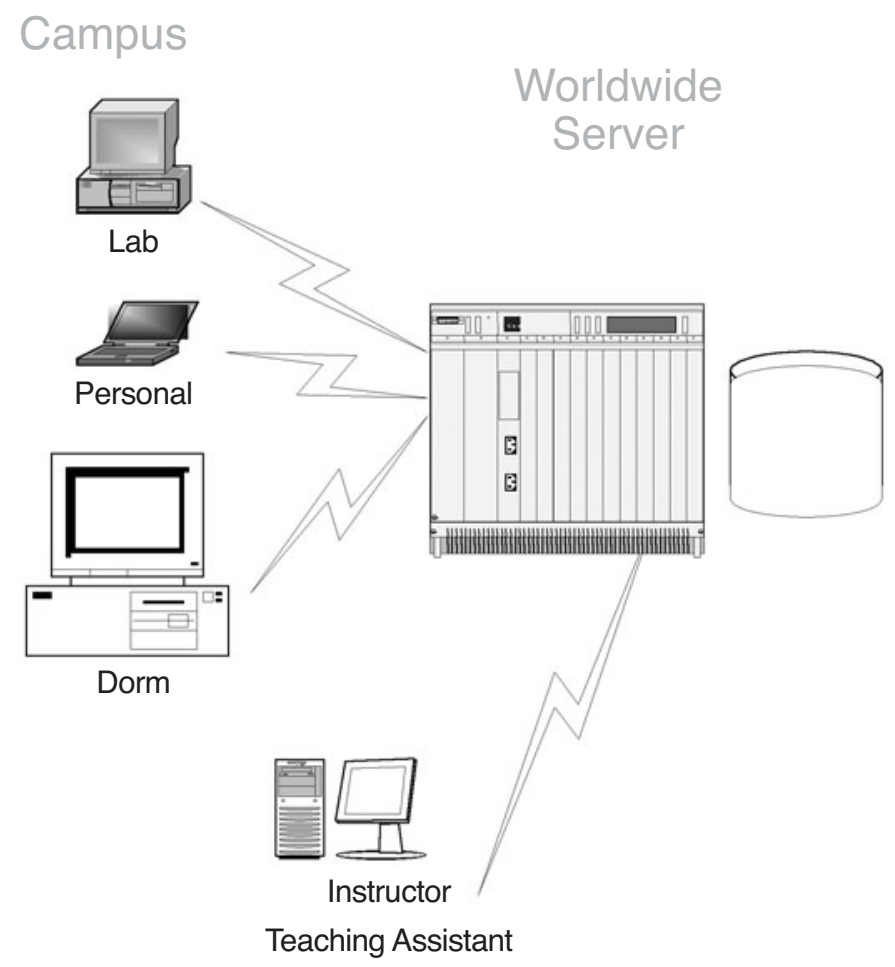

Figure 4. Diagram of network data transfers for analysis.

The typical instructor selects a subset of the experiments from the library. The average number of experiments used in a semester by a class was $6.9(S D=4.2)$. An instructor would typically introduce the topic of an experiment in one class $(15 \mathrm{~min}$ ) and then either have the students run the experiment in class or on their own time ( $\sim 15 \mathrm{~min})$. Then, a few hours or days before the next class, the instructor would download the results and create the lecture materials ( $\sim 15 \mathrm{~min}$ ) using the Excel-based automatic analysis tools. Note that this can also be done in real time (i.e., have the students run the experiment in class, then download and show the results). This can be fun for an early class with a robust experimental result (e.g., Stroop). However, there are risks to "thinking on your feet," so most instructors typically use the "review before class" approach.

Instructors can contrast the results of their class data with the published results or with cumulative data collected from students around the globe who ran the same experiment in previous semesters. The instructor materials include analysis tools, discussion points, PowerPoint slides of the results, suggested extension experiments, and answers to questions posed in the student text. In class, the instructor can make the group data available for student analysis. An effective method of using this data is to require students to look at their own data (they know their own subject number), data for the class section, data for the class, and data for the world. As they see that their personal data do not match the mean, they begin to grasp the importance of variability and the need for averaging and statistical analysis.

Table 1 provides a listing of the experiments and the results of the 5,464 experiments run in the first-year beta program of using PsychMate. The average experiment took $15 \mathrm{~min}$ to run, ranging from $4-33 \mathrm{~min}$. The times shown in Table 1 removed outliers $(0.1 \%$ of the data), which occurred when students paused an experiment (e.g., 16 hours between trials) and then completed it. In the interface, students are asked to set aside a recommended time (which is one standard deviation above the normal time; i.e., we expect $84 \%$ of students to complete the experiment in the suggested time).

Secure, reliable data transfer. One of the initial technological hurdles in the design of PsychMate was to find a way in which the client and server machines could communicate with each other over the Internet. At the time of the design and initial implementation of PsychMate, a number of methodologies were in their infancy or did not have a solid specification that could be relied upon (SOAP, XML, NET). Although there were many techniques that could be used, each had its own drawbacks. A custom design was implemented to facilitate communication between client and server for PsychMate, which solved many of the problems, such as handling communication between client and server over standard Internet protocols, the ability to send and receive binary files, compression and encryption of large data objects, and advanced enhancements such as altering the client ap- 


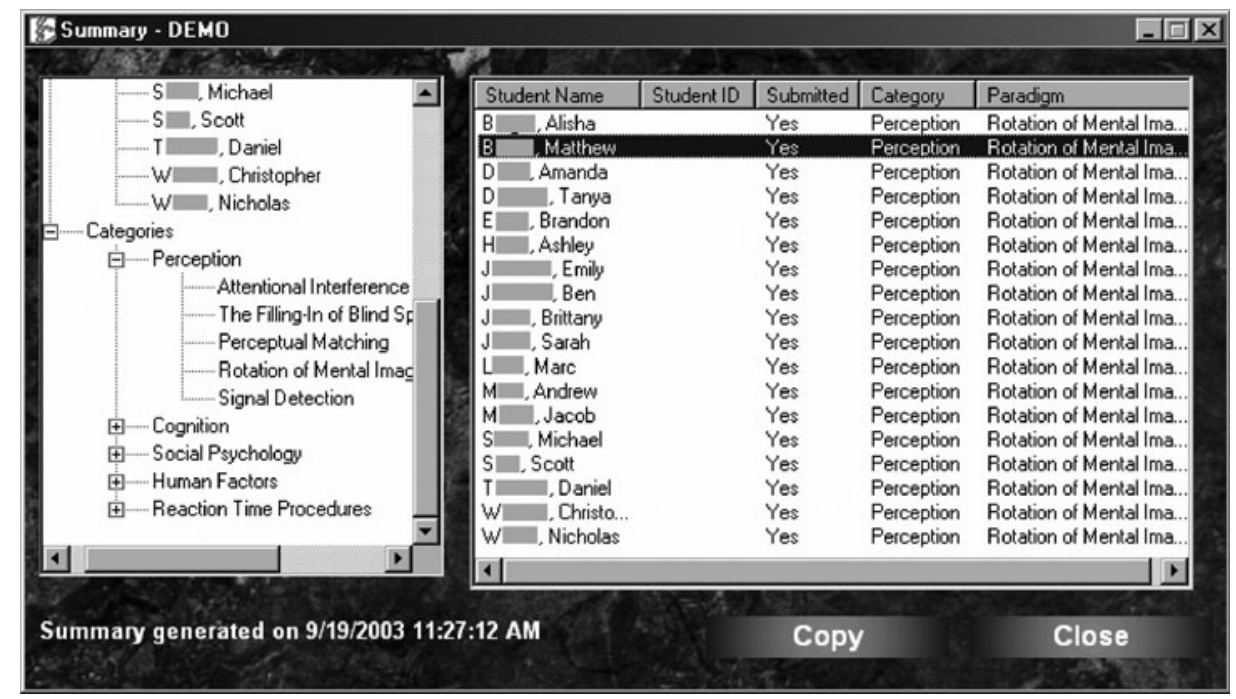

Figure 5. Student participation log. Note that last names are available to the instructor. This image has been altered by graying out last names to protect the anonymity of the subjects.

plication for dynamic features like international text, student scheduling, and the class summary.

A significant challenge was to ensure superior performance, security, and redundancy of data management. The servers on which PsychMate is housed have a historical uptime of $99.9 \%$. Although this figure is well above industry standards, the $0.01 \%$ of downtime per year is very significant for a client server setup in which students may access the system from all around the world at any given time. Significant design and efforts were made to allow several servers to handle requests from PsychMate clients and to ensure that server availability was always in place. If one server becomes unavailable, a backup server can handle the request.

Security was a key challenge. Since student data would be crossing over the Internet, privacy concerns had to be considered. The use of a custom encryption scheme was not advantageous, due to performance issues, requiring additional special software on the client and server computers, and international legal/governmental issues with exportation of the encryption algorithm strength. PsychMate uses the industry standard SSL (secure socket layer) encryption through the HTTPS (hypertext transfer protocol secure) protocol. This method allows for the strongest encryption level the locale permits by law. Since the encryption is industry standard, it has a proven track record for security and reliability and does not require network administrators to configure their firewalls to open $\mathrm{TCP} /$ UDP ports on their networks for a custom application. Files stored locally on the client workstations have an additional layer of encryption for further protection.

Psychology Software Tools was able to overcome the major challenges with the WDSM (Web data submission model) by providing a transparent method for students and users to submit and retrieve data from a shared repos- itory without prerequisite knowledge or learning a number of technical commands. From the student's perspective, the sending and receiving of their subject data occurs automatically. The WDSM recognizes them individually by associating a unique combination of each student's e-mail address and password. After an experiment is run, the WDSM collects the data and automatically submits the data files to the shared repository while the student views a screen indicating the transfer. Any data files needed as the student browses through the system are automatically downloaded without any interaction. In addition, the WDSM provides a student organizer feature for collecting data offline and submitting it at a later time (e.g., for lab or computer environments that are not connected to the Internet at the time of experiment data collection). The instructor interface shares the same underlying technology and is able to retrieve a class section's data files for a particular experiment by clicking on one button on the graphical interface.

The transparent access to the WDSM, server redundancy, thorough documentation, wizard-style initial setup, and intuitive graphical interface have resulted in a very low number of support requests from end users, in comparison with traditional applications. Typically, the number of support requests is less than 3\% of active users per term. Of that small number, most require little further support overhead and are typically resolved by directing the end user to already existing documentation or FAQ (frequently asked question) Web pages.

PsychMate is straightforward to use, and users rarely need support. Psychology Software Tools provides both telephone and e-mail support to instructors. The average number of support requests was 1.5 requests per full semester, with $45 \%$ of sites making no support requests at all. Note that these sites typically have more than 20 stu- 


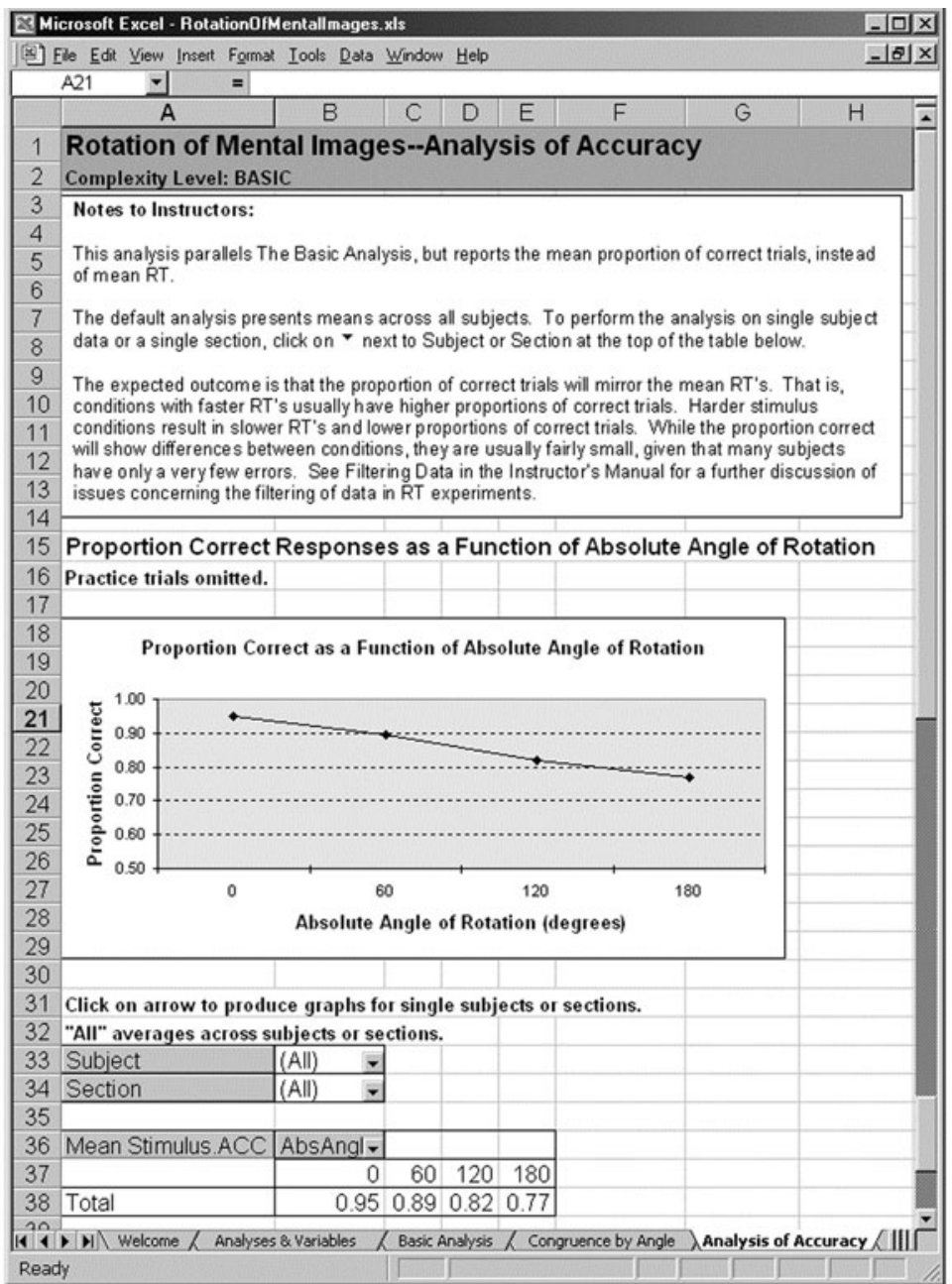

Figure 6. Example of a one-click Excel analysis, showing mean accuracy worksheet (one of 16 worksheets for the experiment).

dents running seven experiments, submitting data, and analyzing results. This suggests that as a student runs an experiment, there is less than a $1 \%$ chance that a student or instructor problem would generate a support request (which typically can be handled in a few minutes).

The WDSM has proven to be a robust system with realworld usage. It has accepted and managed over 18,000 data submissions from students in 2 years, managing over 1,800 user accounts. Instructors on the system average nearly 1,000 downloads of student data per month.

\section{Psychology Experiment Authoring Kit (PEAK)}

For many psychology majors, the pivotal event of their undergraduate careers happens when they take intellectual ownership of a topic, design a novel empirical study, run the experiment, and finally analyze and report the results. A critical tool in PsychMate software allows the authoring of experiments. The Psychology Experiment Authoring Kit (PEAK) is an easy-to-use tool to create new experiments. It uses a smart spreadsheet-based in- terface that enables students with rudimentary skills to create experiments in minutes. Students fill in a spreadsheet listing independent variables and stimuli, then add columns to insert experiment objects such as slides and feedback displays in order to create complete experiments, all within a single spreadsheet. The program then presents the experiment with millisecond timing accuracy and centisecond response accuracy.

In formal usability testing, undergraduate students learned to effectively use PEAK in $2 \mathrm{~h}$ and were able to create a lexical decision experiment in under $10 \mathrm{~min}$ (for more details on the PEAK interface and formal usability testing, see Schneider et al., 2005). Based on responses to the survey item, "Overall, I found the experiment software easy to use," the system was viewed by students to be easy to use [average rating of $3.9(S D=0.8)$ on a 5-point scale; 1-strongly disagree, 3-neither agree nor disagree, 5-strongly agree]. The median undergraduate psychology major (a junior) in the class was able to learn to use PEAK to create a simple experiment in $90 \mathrm{~min}$ of laboratory time. 
Table 1

PsychMate Experiments with Running Times and Test Subject Count

\begin{tabular}{|c|c|c|c|c|c|c|}
\hline Category & PsychMate Name & Version & $\begin{array}{c}\text { Duration in } \\
\text { Minutes }\end{array}$ & $S D$ & $\begin{array}{l}\text { Recommended } \\
\text { Time (min) }\end{array}$ & $\begin{array}{c}\text { Number of } \\
\text { Subjects }\end{array}$ \\
\hline \multirow[t]{17}{*}{ Perception } & The filling-in of blind spots: Induced scotomas & & 7.55 & 5.68 & 13 & 184 \\
\hline & Signal detection & & 25.31 & 5.51 & 31 & 186 \\
\hline & & Probability of signal & 24.23 & 4.33 & 29 & \\
\hline & & Payoffs & 28.36 & 4.37 & 33 & \\
\hline & & Intensity of signal & 25.04 & 7.26 & 32 & \\
\hline & & $\begin{array}{l}\text { Intensity of noise } \\
\text { Random }\end{array}$ & 26.41 & 4.47 & 31 & \\
\hline & Rotation of mental images & & 12.13 & 5.75 & 18 & 493 \\
\hline & & Letters & 11.18 & 4.76 & 17 & \\
\hline & & Shapes & 13.72 & 6.81 & 21 & \\
\hline & Perceptual matching & & 16.17 & 4.79 & 21 & 278 \\
\hline & Attentional interference and the Stroop effect & & 5.80 & 3.00 & 9 & 695 \\
\hline & & Single item-colors & 8.17 & 2.56 & 11 & \\
\hline & & Single item-digits & 8.19 & 2.79 & 11 & \\
\hline & & Multiple item-colors & 4.28 & 2.10 & 6 & \\
\hline & Selective attention and response competition & & 8.53 & 4.08 & 13 & 210 \\
\hline & Iconic memory & & 33.50 & 15.50 & 49 & $\mathrm{v} 2.0$ \\
\hline & Change blindness & & 12.59 & 4.96 & 18 & $\mathrm{v} 2.0$ \\
\hline \multirow[t]{11}{*}{ Cognition } & Lexical decisions & & 9.28 & 3.81 & 13 & 384 \\
\hline & Scanning short-term memory & & 30.54 & 5.66 & 36 & 293 \\
\hline & Typicality in categorization & & 9.49 & 3.68 & 13 & 216 \\
\hline & Sentence-picture comparison & & 16.07 & 4.09 & 20 & 212 \\
\hline & Executive control, planning Tower of London & & 17.91 & 6.23 & 24 & 155 \\
\hline & Organization in memory as an aid to recall & & 26.67 & 10.21 & 37 & 283 \\
\hline & Recall, recognition and encoding specificity & & 6.40 & 5.19 & 12 & 333 \\
\hline & Automatic versus controlled processing & & 24.44 & 8.73 & 33 & 134 \\
\hline & Mental comparisons & & 19.28 & 9.19 & 28 & 216 \\
\hline & Additive factors methodology & & 14.27 & 4.57 & 19 & 70 \\
\hline & The generation effect & & 17.15 & 7.54 & 25 & 157 \\
\hline \multirow[t]{7}{*}{ Social } & The prisoner's dilemma & & 10.34 & 6.54 & 17 & 169 \\
\hline & Measures of personality traits & & 8.22 & 2.81 & 11 & 128 \\
\hline & Impression formation & & 5.04 & 1.96 & 7 & 172 \\
\hline & Levels of processing and the self-reference effect & & 9.82 & 3.05 & 13 & 123 \\
\hline & Automaticity and stereotyping & & 11.30 & 9.76 & 21 & 111 \\
\hline & Survey research & What is sex? & 4.00 & 1.00 & 5 & $\mathrm{v} 2.0$ \\
\hline & & $\begin{array}{l}\text { Tattoos and } \\
\text { piercings }\end{array}$ & 4.00 & 1.5 & 6 & $\mathrm{v} 2.0$ \\
\hline Human factors & Human factors in telephone systems & & 20.92 & 7.91 & 29 & 92 \\
\hline \multirow[t]{2}{*}{ Reaction time } & Reaction time procedures & Number of choices & 11.72 & 2.86 & 15 & 126 \\
\hline & & Stimulus probabilities & 5.44 & 1.54 & 7 & 44 \\
\hline \multicolumn{7}{|l|}{ Cognitive } \\
\hline neuroscience & Working memory & & 17.20 & 15.56 & 33 & $\mathrm{v} 2.0$ \\
\hline
\end{tabular}

Note- - v2.0 features have times based on in-house testing and have not been deployed yet.

Student project subject management. PsychMate includes tools for students to run and collect data on other students via Web management of the experiment and data management enterprise. PsychMate and PEAK will soon include an Experiment Deployment Model (XDM), which will permit experiment authors to deploy their custom experiments to a shared area on the Web. The experiment author will be able to allow public access to the experiment or to protect it with a pass code. The instructor will have the option to approve or disapprove the experiment for deployment (e.g., verify human subjects and content issues). Once an experiment is deployed, other students may access it, and necessary files will be automatically downloaded by PsychMate without further user interaction. After the download is completed, the student subject will run the experiment. Any data collected will then be automatically uploaded to the Web, where the experiment author may later review and analyze the data from the entire subject pool. Advanced features expected for the XDM will be to enable the experiment to automatically generate subject numbers, to allow the experiment author to view reports on experiment usage, and to automatically perform common analyses on the subject data. It will also track subject participation in experiments. As a rule, students are encouraged to contribute a minimum number of hours (e.g., $5 \mathrm{~h}$ ) to the pool and $20 \%$ more hours than they take from the pool. Options can be set to collect data across institutions.

Human subjects permission and running. The data generated from student-created experiments must be collected according to the rules for protection of human subjects in educational settings. These guidelines 
can be obtained from the Department of Health and Human Services - National Institutes of Health Office for Protection from Research Risks, Part 46-Protection of Human Subjects (available at http://www.hhs.gov/ ohrp/humansubjects/guidance/45cfr46.htm\#46.101). This exempts

Research involving the use of educational tests (cognitive, diagnostic, aptitude, achievement), survey procedures, interview procedures or observation of public behavior, unless (i) information obtained is recorded in such a manner that human subjects can be identified, directly or through identifiers linked to the subjects; and (ii) any disclosure of the human subjects' responses outside the research could reasonably place the subjects at risk of criminal or civil liability or be damaging to the subjects' financial standing, employability, or reputation.

Note that PsychMate hides any identifying information before it is made available to the researcher. Subjects must consent to have their data collected, must be at least 18 years of age to participate, and are free to withdraw at any time. ${ }^{2}$ The participation logs cannot be viewed until $20 \%$ of the subject sessions have been logged and are only updated either weekly or when at least 5 new subjects have been added so that no one can continu- ously monitor participation logs to match a new data set to a subject. The participation $\log$ s that identify the student names are only made available to the instructor and are not connected to the data sets made available to students.

With these tools, a typical student project would go through the following steps. The students would work on the experiment and pilot test it on themselves and perhaps a few friends. They would then submit the experiment to the provisional experiment queue via the Web, including a description of the experiment, experimenter contact information, and agreement to maintain data confidentiality and abide by human subject guidelines. The instructor would then review the materials (including potentially running the experiment) and release the experiment to the run queue. Then a description of the experiment would appear on the class Web list of experiments. Other students would then participate in the study and have their participation hours logged (maintained separately from the data). The students could then download their data from the server, run the analysis, and write up the study. Note that neither the subject, the student experimenter, nor the instructor can identify a given data set as coming from a particular subject. ${ }^{3}$

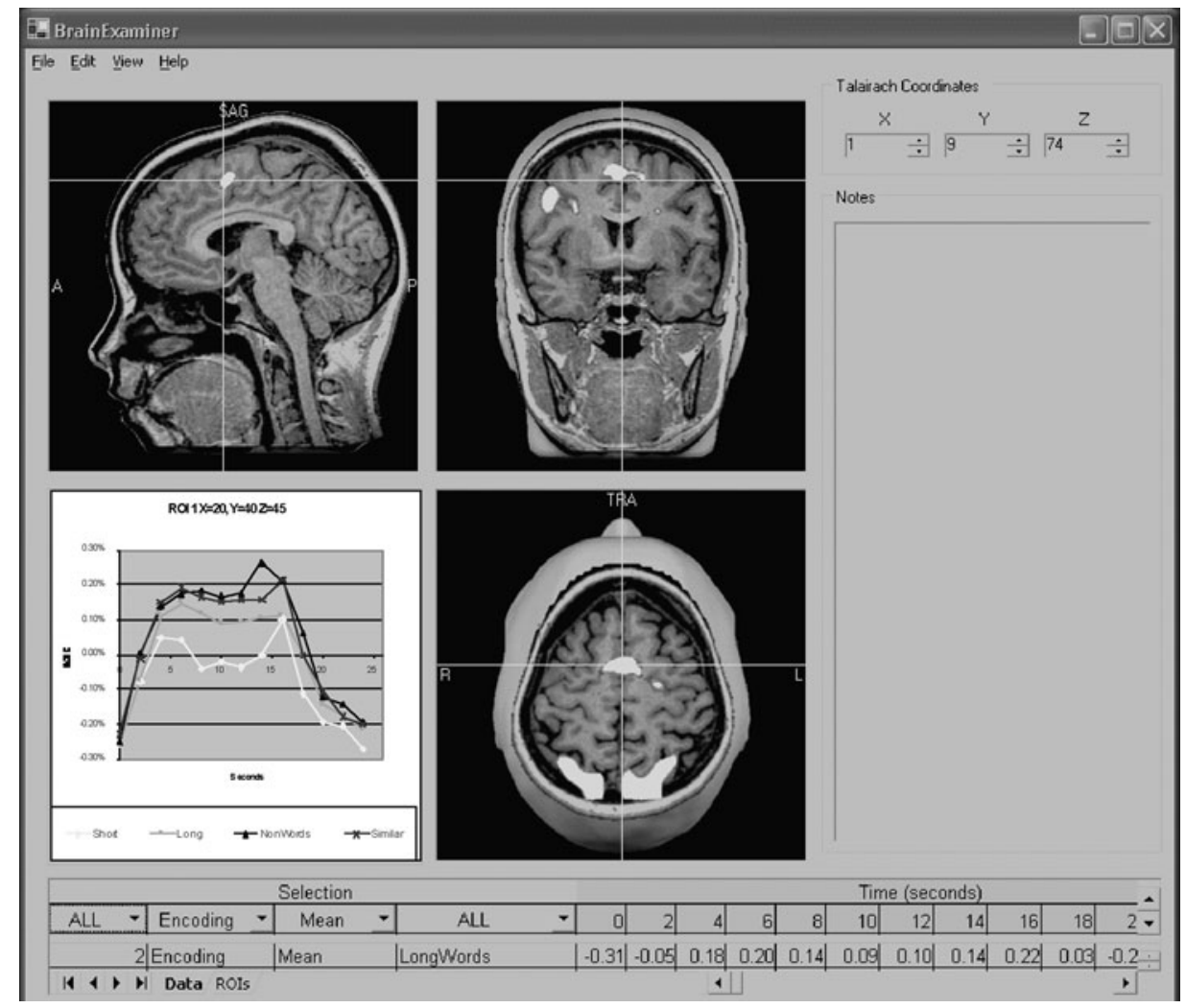

Figure 7. The BrainViewer activation tracking program allows students to move through the brain, clicking on regions of interest and then examining the activation time course (lower left) of the areas. The lower spreadsheet allows students to select contrasts, subjects, and conditions to characterize activation patterns and variability. 


\section{Cognitive Neuroscience Tools}

Cognitive neuroscience is an exciting new area of psychology. Students find it very interesting to look inside brains, watch activity, and try to understand brain function. PsychMate includes a set of tools to nurture this interest and to teach about cognitive neuroscience. Given the high expense and technical demands of most brainimaging studies (e.g., \$1,000 per subject for a 1.5-h fMRI study), we cannot make such equipment available for undergraduate projects at textbook prices. However, we can provide students with their own behavioral data complemented by data from current, published imaging studies. Students can collect data on themselves in behavioral experiments that were run in a brain-imaging context (e.g., looking at rehearsal during a working memory task). They then compare their personal behavioral data with the published results and can analyze their data with the imaging data from other subjects.

BrainViewer. PsychMate includes a BrainViewer tool (see Figure 7) that allows students to navigate through a person's brain, click on highly active areas, examine the dynamic activity of those regions, and label brain areas. As they perform exercises included in PsychMate, they rapidly become aware of the complexities of looking at brain data (e.g., different subjects show different patterns, averaging is necessary, there is a need to correct for technical issues such as hemodynamic delay of the blood flow response, etc.). Students come to realize that a brain image by itself tells little and that only through carefully designed contrasts of conditions can we gain significant insights about the operation of the brain. This supports and motivates the teaching of the behavioral methods that students learn in the classroom.

BrainTutor. With the growing use of brain imaging, all areas of psychology are making reference to different brain regions and how they interact. It is difficult for students (and instructors) to learn the names and locations of brain regions (e.g., where is the dorsolateral prefrontal cortex [DLPFC] for executive function, or the amygdala for emotional coding?). To facilitate learning brain regions and to aid in the analysis of imaging results, PsychMate includes the BrainTutor (Figure 8), developed by Rainer Goebel (available at http://www.brainvoyager.com/BrainTutor. html). BrainTutor conveys knowledge about the human brain in a simple way. The program lets a student interactively explore high-quality 3-D head and brain models, which can be rotated, moved, and zoomed in or out in real time. The program contains information about the major lobes, gyri, and sulci of the cerebral cortex, which are revealed in color simply by clicking on a part of the brain. It also shows data in both orthographic views and 3-D rendered views. PsychMate includes BrainTutor exercises in which students identify cortical areas, learn the standard Talairach cortical coordinate system, and develop the ability to go from activation in the BrainViewer to identifying the name of the related cortical regions the in BrainTutor.

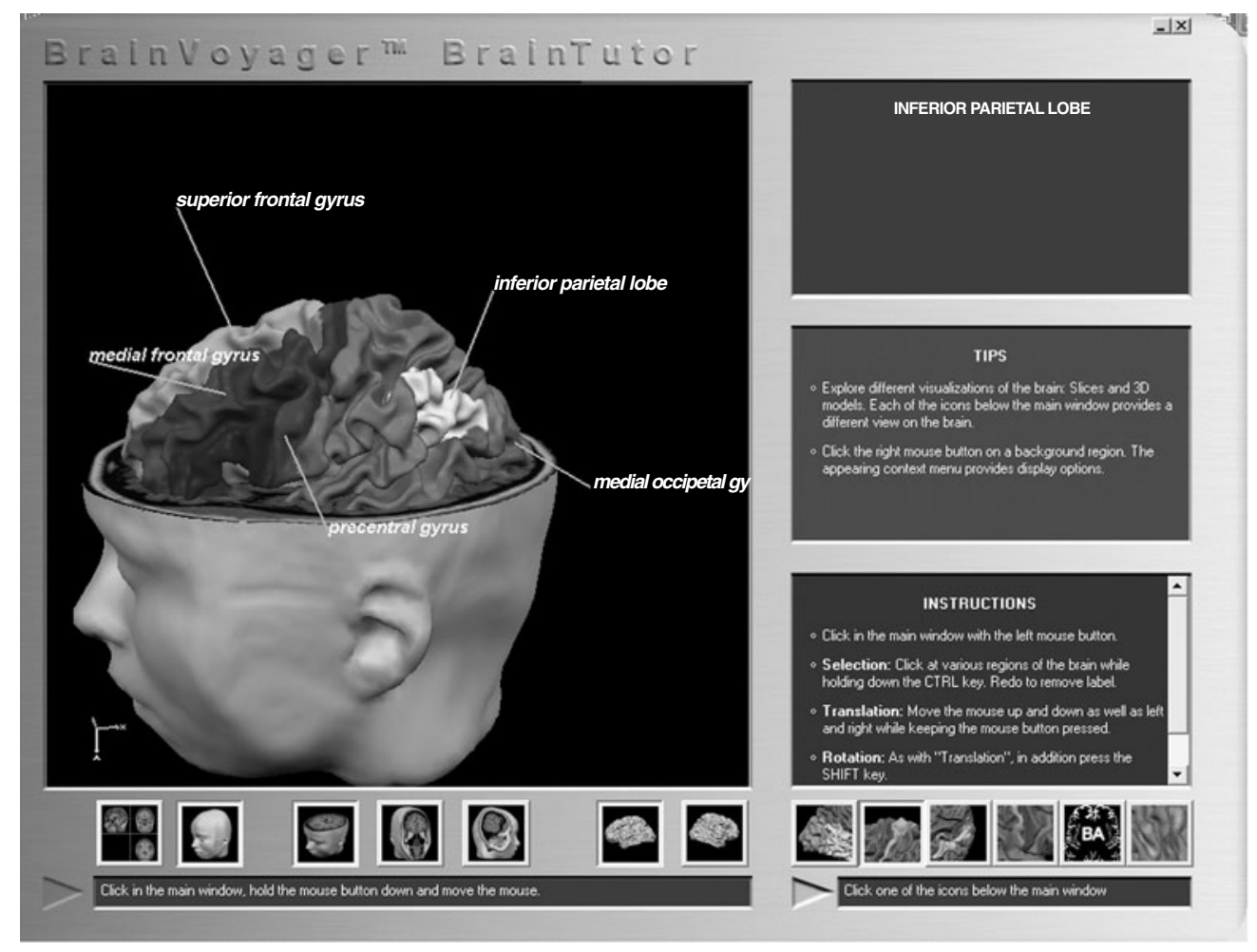

Figure 8. The BrainTutor is designed to explore cortical anatomy. A student can examine data in orthographic or 3-D rendered views by clicking on different areas. 


\section{Methodology for a Growing Body of Tools}

PsychMate provides a foundation upon which tools can be accessed, incorporated, distributed, and managed. In the future, we plan to expand this dual behavioral/ processed specialty data approach (which can be run by oneself in a behavioral experiment, analyzing data coming from specialized equipment) to multiple domains, including ERP, eye movement monitoring, and physiological monitoring. This provides a good foundation for upper level courses in which students can obtain exposure to techniques that they may later use in independent study in research laboratories.

Our implementation strategy is to develop PsychMate lessons using new technology through a staged testing cycle. For each tool, we provide consistently formatted documentation that can be understood by the typical undergraduate psychology student. We carry out user testing to tune the materials (see Schneider et al., 2005). The tools and documentation are used in a beta testing mode at a few carefully monitored sites. Then the tools become part of the standard toolkit for all undergraduates to use. In this way, instructors can incorporate easyto-use, well-documented, fairly bug-free programs quickly and relatively painlessly into the curriculum. Current tools in development include videotape and behavioral event coding questionnaire surveys.

Conclusion. The training of psychology undergraduates is a major mission of colleges involving hundreds of thousands of students. Learning empirical methods and developing skills for interpreting and using those methods are critical for their knowledge. Many daunting challenges make it difficult for psychology instructors to provide effective training to students. PsychMate has addressed most of these challenges so that students can use either laboratory or personal computers to run, analyze, develop, and report on experimental results. This can be done even under the tight budgetary and time limitations operating in most psychology departments. Ten years ago, few psychology students had access to, or knew how to use, spreadsheets, presentation programs, and comprehensive word processing. PsychMate provides a model of how to develop, test, and deploy a comprehensive set of tools to meet the needs of today's psychology majors.

\section{REFERENCES}

Chase, C. H., \& ABboud, H. (1997). SuperLab LT: Experimental software for psychology students. Phoenix: Cedrus.
Chute, D. L. (1986). MacLaboratory for psychology: General experimental psychology with Apple's Macintosh. Behavior Research Methods, Instruments, \& Computers, 18, 205-209.

Cohen, J., MacWhinney, B., Flatt, M., \& Provost, J. (1993). PsyScope: An interactive graphic system for designing and controlling experiments in the psychology laboratory using Macintosh computers. Behavior Research Methods, Instruments, \& Computers, 25, 257-271.

Francis, G., Neath, I., Mackewn, A., \& Goldthwaite, D. (2004). Student manual for CogLab. Belmont, CA: Wadsworth.

HoRnBy, P. A., \& ANDERSON, M. D. (1994). Computer use in psychology instruction: A survey of individual and institutional characteristics. Behavior Research Methods, Instruments, \& Computers, 26, 250-254.

LEVY, C. M., \& RANSDELL, S. E. (2000). Laboratory in cognition and perception (3rd ed.). Gainesville, FL: Psychology Software.

MacWhinney, B., St. James, J. [D.], Schunn, C., Li, P., \& Schneider, W. (2001). STEP - A System for Teaching Experimental Psychology using E-Prime. Behavior Research Methods, Instruments, \& Computers, 33, 287-296.

ST. JAMES, J. D. (1989). The MEL library in the undergraduate research methods course. Behavior Research Methods, Instruments, \& Computers, 21, 245-247.

St. JAMES, J. D., \& SCHNEIDER, W. (1991). Student MEL software support for instructors and teaching assistants in research methods course. Behavior Research Methods, Instruments, \& Computers, 23, 149-154.

St. James, J. D., Schneider, W., \& Rodgers, K. A. (1994). MEL LAB: Experiments in perception, cognition, social psychology and human factors. Pittsburgh: Psychology Software Tools.

SCHNEIDER, W. (1988). Micro Experimental Laboratory: An integrated system for IBM PC compatibles. Behavior Research Methods, Instruments, \& Computers, 20, 206-217.

Schneider, W., Bolger, D. J., Eschman, A., Neff, C., \& Zuccolotto, A. P. (2005). Psychology Experiment Authoring Kit (PEAK): Formal usability testing of an easy-to-use method for creating computerized experiments. Behavior Research Methods, 37, 312-323.

SORKIN, R. D. (1997). Projects in experimental psychology. Bayport, NY: Life Science Associates.

Williams, J. E., McGraw, K. O., \& Tew, M. D. (1999). Undergraduate labs and computers: The case for PsychExps. Behavior Research Methods, Instruments, \& Computers, 31, 287-291.

\section{NOTES}

1. Since many student laboratories do not allow student installation of software, instructors are able to install the software on all campus computers without charge. Students can then sign onto their account on the laboratory computers.

2 . To be consistent with human subjects guidelines, students must be free to opt out of participation and substitute some other activity (e.g., writing a report on a related research topic) if they choose not to participate in experiments.

3. Note that technically, the subject could answer questions in a unique fashion and if the experimenter made the data available to the subject, he or she could potentially recognize him- or herself.

(Manuscript received December 8, 2004; revision accepted for publication April 1, 2005.) 